\title{
Car driving for the severely physically disabled: the American experience
}

\author{
J Shand, J P Sivewright, DipPTG (Admin and Tech Studies) \\ 9 Almond Court, Thistle Foundation, Edinburgh, Scotland
}

Let us imagine that an extremely disabled man comes to you and states that he wishes to drive again. What is your reaction? If I go on to explain that this man has muscular dystrophy, is totally dependent, requires all his personal needs attended to, including feeding, has virtually no arm or leg movement, weak neck muscles, no lateral balance, and if you remove the strap from around his chest he would fall forward, does that clarify things any? $\mathrm{He}$ is what the Americans call 'totally immobile'. He does have some weak wrist action, which allows flipper like movement of his hands. Would you support his request, or would you think that he was being totally unrealistic, and that it was your duty to bring him down to earth?

I would imagine that it would probably be the latter course. You see, there is no way he can drive safely. Apart from the problem of lateral balance, what is he going to drive with? He has insufficient power in either arm to operate a conventional joystick. How is he going to change gear, indicate, use his windscreen wipers? How is he going to start it, when he is too weak to turn a key? Definitely cloud cuckoo land ... perhaps you could arrange for some counselling?

Yes, I know, for I am that disabled person, and despite all I was told, remained determined to get on the road again. Professionals distanced themselves from this effort, believing that I must be disappointed at the end of the day. I now have my car, which I can enter and exit and drive independently! It was not an easy exercise, and it was not cheap, but the technology is there, even if I had to go to America to find it. The car is now one year old, and I have safely covered 10,000 miles, and my whole lifestyle has changed. So, how did they do it?

Apparently, if you are in my position in the United States, an assessor comes and checks all the movements you have. Then, a prescription for hand controls is written, which is precise down to the last millimetre. This then goes to a company called Ahnafield Corporation, who do the majority of this kind of work, and are based in Indianapolis. However, not living in the United States, I had to go personally to be fitted for the Chrysler Entervan. There was no dubiety about my capability to drive, as there had been in this country. The philosophy was 'If you have the determination to get here, we have the technology to put you on the road'.

So, after many hours, they had the measurements, had assessed what little I could do, and described how they were going to modify the car. The floor had already been lowered 10 inches, air kneeling suspension and an automatic ramp inserted (Fig 1) so they were merely concerned with the hand controls. It was explained that I would use a joystick which would be very light, as it was operated by electrics over hydraulics. It would work from voltage pressure, and this pressure could be increased if $I$ required it at a later date. It would have four way function, controlling brake and accelerator as well as left and right turn. So, I pull back to accelerate, forward to brake and left and right to steer. Simple! It seemed so easy, and the joystick

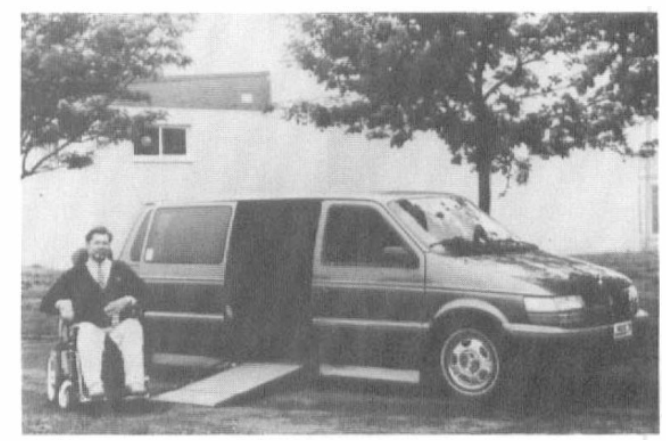

Figure 1 The Chrysler Entervan. 
was so incredibly light. For all the other functions, they were installing a computer, which has a similarity to possum, in that you scan down until you find the function you want. Thirty functions are controlled from this box, which is no bigger than a packet of cigarettes! Not only could I start the car, change gear and everything else, but I could alter my heating, wind down the windows and turn on the radio. It was absolutely wonderful! Being able to control these things after having to ask for so long, seemed complete luxury.

In case you are wondering, no, this doesn't come cheap, and no, I am not wealthy. However, once the Government launched it's Motability project, offering $£ 30,000$ per individual who wished to drive, I thought it was made for me! At the end of the day, because of delays in this country, the level of grant was dropped and I was only given $£ 16,000$. (I was looking for a total of $£ 40,000$ !) Through severe efforts at fundraising, I eventually reached my target. No mean task for an individual in the middle of a recession.

You might be concerned as to how we overcame the balance problem ... I ordered a Vessa wheelchair in this country, and had them fit a Recaro chair to it, which stopped me falling forward, because it has a bucket seat. In America side supports were added, so that it was impossible for me to fall sideways. Hardware was also installed underneath the wheelchair to connect to the Latchlok system, which holds the chair in place when I am driving. If I become disconnected in transit, an alarm sounds. If I wish to uncouple the chair to exit the van, I press a button on the right arm of my wheelchair. A velcro strap was attached to the left side of my wheelchair, to keep my arm in place while operating the computer, as it was discovered that if this arm fell, I could not move it back into position myself. I still wear a belt round the chair for safety and convenience. I clip all my remote controls to the belt - garage door, burglar alarm and automatic car door and ramp. Once on the road, I discovered several things ... one was that I could not see what was coming from either side if I was at a junction. I overcame this by adding internal mirrors to the car. The other problem was the joystick. It was light enough, and stalks had been added to hold my wrist securely, but it was a flat metal triangle, and I felt I would have more control if there was something in the palm of my hand. This was achieved by adding plasticine, until we got the right height, and then applying it securely (Fig 2).

Even with all this equipment, I can hear you asking, 'Is it really safe?' The answer is, it has to be. Americans are so frightened of being sued, they would not dare put someone like me on the road without being $100 \%$ convinced of my safety. The electronic joystick, therefore, has been wired twice. If there is a problem with my steering, I can switch over to the secondary system, which will get me out of trouble. Should there be a power failure, when brakes and steering would not function, there is a back up pump which will come on to assist the steering, and I can either push the joystick full forward or press a button which will bring on the emergency brake.

I was told in America that this company had not failed to put anybody on the road yet, and that people far more disabled than I, were enjoying driving. I wondered out loud how much more disabled one could get, and was told the story of a girl with no arms and legs at all, where they had mounted the joystick in the roof, and supplied her with a special helmet to connect to it! It was an experience to hear of this forward thinking and to benefit from such positive attitudes. Until we change our basic attitude in Britain, we will never make the progress that has been made in

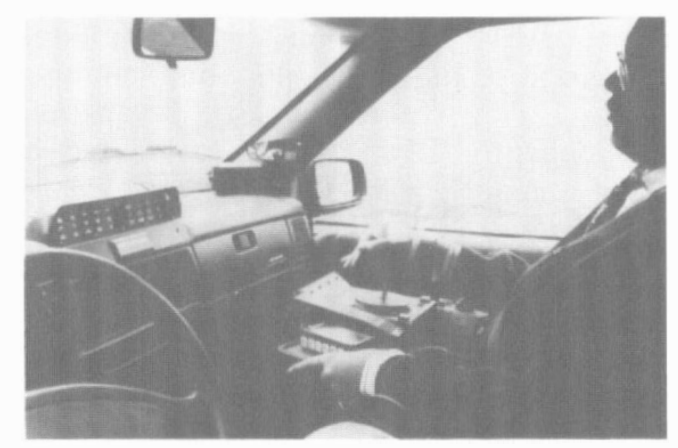

Figure 2 The electronic joystick. 
discharge data is about $90 \%$, but this excludes persons who die before reaching the hospital and those who are hospitalised out of state. More complete ascertainment of the incidence of SCI in a population requires surveillance systems that include reports from vital records or medical examiner records.

\section{Acknowledgements}

The authors express appreciation to Edma Diller, Craig R Nichols, Gerrie Thompson, and Gayle Wood for their assistance in this project. This study was funded by a grant from the US Centers for Disease Control and Prevention, National Center for Injury Prevention and Control.

\section{References}

1 Kraus JF, Franti CE, Riggins RS et al (1975) Incidence of traumatic spinal cord lesions. J Chron Dis 7: 471-492.

2 Black WA, Jr, Albin M, Aronica MJ et al (1978) A comprehensive plan for spinal cord injury services in Pennsylvania. Penn Med 81: 29-54.

3 Kalsbeek WD, McLaurin RL, Harris BSH, Miller JD (1982) The national head and spinal cord injury survey: major findings. J Neurosurg 53: S19-S43.

4 Bracken MB, Freeman DH, Hellenbrand K (1981) Incidence of acute traumatic hospitalized spinal cord injury in the United States, 1970-1977. Am J Epidemiol 113: 615-622.

5 Centers for Disease Control (1988) Acute traumatic spinal cord injury surveillance-United States, 1987. MMWR CDC Surveill Summ 37: 285-286.

6 National Committee for Injury Prevention and Control (1989) Injury Prevention: Meeting the Challenge. Oxford University Press, New York: 290.

7 Health Care Financing Administration (1989) International Classification of Diseases, 9th Revision, Clinical Modification, 3rd edn. US Department of Health and Human Services, Washington DC.

8 Centers for Disease Control (1988) Guidelines for evaluating surveillance systems. MMWR CDC Surveill Summ 37: S-5: 1-18.

9 American Spinal Injury Association (1982) Standards for neurological and functional classification of spinal cord injury. American Spinal Injury Association, Chicago.

10 Thurman DJ, Burnett CL, Beaudoin DE et al (1993) Risk factors and mechanisms of occurrence in motor-vehicle-related spinal cord injuries: Utah. 37th Annual Proceedings. Association for the Advancement of Automotive Medicine, Des Plaines, Illinois: 201-208.

11 Alker GJ Jr, Oh YS, Leslie EV (1978) High cervical spine and craniocervical junction injuries in fatal traffic accidents: a radiological study. Orthop Clin North Am 9: 1003-1010.

12 Bucholz RW, Burkhead WZ, Graham W, Petty C (1979) Occult cervical spine injuries in fatal traffic accidents. J Trauma 19: 768-771. 